\begin{tabular}{|c|c|}
\hline 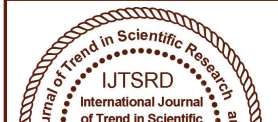 & $\begin{array}{l}\text { International Journal of Trend in Scientific Research and Development (IJTSRD) } \\
\text { International Open Access Journal | www.ijtsrd.com }\end{array}$ \\
\hline 04 & ISSN No: 2456 - 6470 | Volume - 2 | Issue - 6 | Sep-Oct 2018 \\
\hline
\end{tabular}

\title{
A Correlation Between Leg-Heel Alignment, Tibial Torsion and Q Angle Amongst Ideal, Overweight and Obese Individuals
}

\author{
E. Jayakanthan ${ }^{1}$, Rijula Raj. $\mathbf{R}^{2}$ \\ ${ }^{1}$ Assistant Professor, ${ }^{2}$ Master of Physiotherapy- Student \\ SRM college of Physiotherapy, Kattankulathur, Kanchipuram, Tamil Nadu, India
}

\begin{abstract}
BACKGROUND: Excess weight puts a strain on every part of the body. The position and function of the foot and ankle affect the stresses transmitted to the knee.
\end{abstract}

OBJECTIVE: To measure and to find correlation between leg-heel alignment, Tibial torsion and Q angle in ideal, overweight and obese.

STUDY DESIGN: Non experimental, observational study.

PROCEDURE: 75 subjects were conveniently selected based on Inclusion and Exclusion Criteria and divided in to 3 groups. ideal subjects with BMI prime between 1.0 to 1.2 were Group- A, overweight subjects with BMI prime 1.0 to 1.2 were Group-B and obese subjects with BMI $>1.2$ were group $\mathrm{C}$. Of each subject leg -heel alignment, Tibial torsion, $\mathrm{Q}$ angle will be measured using measuring tape, goniometer and correlation is studied.

RESULTS: There was significant difference $Q$ angle between ideal-Overweight $(\mathrm{p}=0.001)$, ideal-Obese $(p=0.001)$, Obese - Overweight $(p=0.001)$ in Right .ideal - Overweight $(p=0.001)$, Normal -Obese $(p=0.000)$ in Left. For leg heel alignment There was significant difference between ideal-Overweight, ideal-Obese, Overweight-Obese $(\mathrm{p}=0.000)$.

Keyword: Obesity, $Q$ angle, Leg heel alignment, Tibial torsion.

\section{INTRODUCTION}

Obesity is the excess or abnormal accumulation of the body fat, the incidence of obesity is increasing rapidly. Worldwide overweight and obesity are major health problems where the body weight is $>20$ percentage of the ideal. Obesity affects the quality and quantity of life and increases risk of mortality due to associated co-morbidities .Excess weight puts a strain on every part of your body.

The co-morbidities includes hypertension Dyslipidemia, Diabetes mellitus, coronary heart disease, stroke, Gallbladder disease, sleep apnea, Osteoarthritis, Respiratory problems ,Cardiovascular disease, Gout, Cardiac arrhythmias and cancer like endometrial, breast, prostate and colon cancer and many musculoskeletal disorder like foot problems in obese adults are most important. Stress on bones, tendons, ligament increases due to additional weight.

Obese individuals have lower relative less muscle strength compared to non obese individual. Weakness and susceptibility to fatigue of certain key muscles (e.g. vastus and gluteus medius) can result in abnormal gait pattern due to their critical role in locomotor tasks, predisposing individuals to musculoskeletal injury or pathology. The degree to which obesity affects gait kinematics and kinetics is not clear some studies reports that kinematics are similar in obese and non obese .Musculoskeletal stimulations can provide us with an improved understanding of the force requirements and roles that individual muscles play during locomotor tasks. Musculoskeletal function impairment such as abnormal mechanics of the body is the consequence of increased stress within the bones. Determination of the $\mathrm{Q}$ angle is particularly important for patients who are involved in competitive or recreationl sports and also in female patients who walk for health or climb stairs frequently. When measured the $\mathrm{Q}$ angle should fall between 18 degrees and 22 degrees. Males are 
usually low end of this range, while females (because of wider pelvis) tend to have higher measurements Slight variation in the patient positioning have a significant effect on the measurement of the Q angle, and measurement reliability in the supine position is only moderate.

The most effective way to decrease a high $\mathrm{Q}$ angle and the lower the biomechanical stresses on the knee joint is to prevent excessive pronation with flexible orthotics. It is important that good biomechanical function is restored to all joints of both lower extremities. Stretching of tight muscle and strengthening of weak areas should be included. Muscles commonly found to be tight include the quadriceps, hamstring, iliotibial band and gastrocnemius

\section{AIM}

The correlation between leg -heel alignment, tibial torsion and $\mathrm{Q}$ angle amongst ideal, overweight and obese individuals.

\section{NEED OF THE STUDY}

To measure and to find correlation between leg-heel alignments, tibial torsion and $\mathrm{Q}$ angle among on ideal, overweight and obese individuals and to find the structure that is more affected Health education to improve the quality of life of the individuals.

\section{PROCEDURE}

75 subjects were conveniently selected based on Inclusion and Exclusion Criteria and divided in to 3 groups. Group- A Normal subjects with BMI range between 18.5 to 22.9 ,Group- B overweight subjects with BMI range between 23.0 to 24.9 and Group C Obese subjects with BMI more than 25.0.Of each subjects leg-heel alignment, Tibial torsion and $\mathrm{Q}$ angle will be measured. $Q$ angle was measured by placing lower limbs at right angle to the line joining two ASIS. A line was drawn from ASIS to midpoint of patella on the same side and from the tibial tubercle to the midpoint of the patella. The angle formed by crossing these two lines is Q angle which normally is 13 degree for male and 18 for females.

\section{MEASURING THE TIBIAL TORSION}

The subject is in sitting position with the knee flexed to 90 degrees. The foot prints was taken on the blank paper. The medial and lateral malleolus point was marked on the paper and these point will be and these points was joint to form tibial torsion angle was measured. The angle formed is 12 degree to 18 degree normally.

\section{MEASURING THE LEG HEEL ALIGNMENT-}

The subject lies in the prone position with foot extending over the end of the examining table. Then a mark is placed over the midline of the calcaneus at the insertion of the Achilles tendon, A second mark is made $\sim 1 \mathrm{~cm}$ distal to the first mark and as close to the midline of the calcaneus as posible. A calcaneal line is then made to join the two marks. Next, two marks is made on the lower third of the leg in the midline forming the tibial line, which represents the longitudinal axis of the tibia. Now the subtalar joint is placed in the prone neutral position. While the subtalar joint is held in neutral the two lines are studied. Health education is provided to the subjects of the study. Q Angle, tibial torsion and leg -heel alignment were statistically analyzed amongst ideal overweight and obese using ANOVA and comparison between 2 groups was analyzed using Data analysis.

TABLE 1 GENDER DISTRIBUTION AMONG GROUP A

\begin{tabular}{|c|c|c|c|c|}
\hline & & FREQUENCY & PERCENT & VALID PERCENT \\
\hline \multirow{3}{*}{ VALID } & WOMEN & 14 & 56.0 & 56.0 \\
\cline { 2 - 5 } & MEN & 11 & 44.0 & 44.0 \\
\cline { 2 - 5 } & TOTAL & 25 & 100.0 & 100.0 \\
\hline
\end{tabular}

This table shows that out of 25 individuals , 56\% were women and $44 \%$ were men who fell under the normal category (18.5-22.9) of body mass index calculation.

TABLE 2 GENDER DISTRIBUTION AMONG GROUP B

\begin{tabular}{|c|c|c|c|c|}
\hline & & FREQUENCY & PERCENT & VALID PERCENT \\
\hline \multirow{3}{*}{ VALID } & WOMEN & 17 & 68.0 & 68.0 \\
\cline { 2 - 5 } & MEN & 8 & 32.0 & 32.0 \\
\cline { 2 - 5 } & TOTAL & 25 & 100.0 & 100.0 \\
\hline
\end{tabular}


International Journal of Trend in Scientific Research and Development (IJTSRD) ISSN: 2456-6470

This table shows that out of 25 individuals , $68 \%$ were women and $32 \%$ were men who fell under the obese category (23.0-24.9) of body mass index calculation.

TABLE 3 GENDER DISTRIBUTIONS AMONG GROUP C

\begin{tabular}{|c|c|c|c|c|}
\hline & & FREQUENCY & PERCENT & VALID PERCENT \\
\hline \multirow{3}{*}{ VALID } & WOMEN & 16 & 64.0 & 64.0 \\
\cline { 2 - 5 } & MEN & 9 & 36.0 & 36.0 \\
\cline { 2 - 5 } & TOTAL & 25 & 100.0 & 100.0 \\
\hline
\end{tabular}

This table shows that out of 25 individuals , $64 \%$ were women and $36 \%$ were men who fell under the over weight category ( more than 25.0 ) of body mass index calculation.

TABLE 4 COMPARISON OF Q ANGLE AMONG THE GROUPS.

\begin{tabular}{|c|c|c|}
\hline & RIGHT & LEFT \\
\hline IDEAL & 15.60 & 15.80 \\
\hline OVERWEIGHT & 17.88 & 18.24 \\
\hline OBESE & 19.40 & 19.56 \\
\hline F VALUE & 18.887 & 18.260 \\
\hline P VALUE & 0.000 & 0.000 \\
\hline
\end{tabular}

This table shows that there was significant difference of $\mathrm{Q}$ angle between ideal-Overweight $(\mathrm{p}=0.001)$, idealObese $(p=0.001)$, Obese - Overweight $(p=0.001)$ in Right. ideal - Overwight $(p=0.001)$, ideal -Obese $(p=0.000)$ in Left .And No significant difference was seen between Overweight-Obese ( $p>0.099)$ in left.

TABLE 5 COMPARISON OF LEG HEEL ALIGNMENT AMONG THE GROUPS.

\begin{tabular}{|c|c|c|}
\hline & RIGHT & LEFT \\
\hline IDEAL & 3.92 & 4.36 \\
\hline OVERWEIGHT & 5.12 & 5.12 \\
\hline OBESE & 5.96 & 6.40 \\
\hline F VALUE & 108.49 & 132.867 \\
\hline P VALUE & 0.000 & 0.000 \\
\hline
\end{tabular}

This table shows that, there was significant difference of leg heel alignment between ideal-Overweight, ideal-Obese, Overweight - Obese $(\mathrm{p}=0.000)$

TABLE 6 COMPARISON OF TIBIAL TORSION AMONG THE GROUPS.

\begin{tabular}{|c|c|c|}
\hline & RIGHT & LEFT \\
\hline IDEAL & 12.68 & 12.80 \\
\hline OVERWEIGHT & 15.92 & 16.32 \\
\hline OBESE & 15.80 & 15.96 \\
\hline F VALUE & 315.037 & 255.745 \\
\hline P VALUE & 0.000 & 0.000 \\
\hline
\end{tabular}

This table shows that, there was significant difference of tibial torsion between ideal-Overweight,ideal-Obese $(p=0.000)$ in both right and left side. No significant difference was seen between Overweight-Obese $(p>0.692)$ in right, $(\mathrm{p}>0.097)$ in left.

TABLE 7 THE CORRELATION BETWEEN THE Q ANGLE AND TIBIAL TORSION IN RIGHT

\begin{tabular}{|c|c|c|c|}
\hline VARIABLES & N & SIGNIFICANT VALUE & PEARSON CORRELATION \\
\hline Q ANGLE RIGHT & 75 & 0.000 & 0.520 \\
\hline TIBIAL TORSION RIGHT & 75 & 0.000 & 0.520 \\
\hline
\end{tabular}

The above table shows the variables, $\mathrm{N}$ value, significant value $(\mathrm{p}=0.000)$ and pearson correlation between the $\mathrm{Q}$ angle and tibial torsion among the group in right side. 
International Journal of Trend in Scientific Research and Development (IJTSRD) ISSN: 2456-6470

TABLE 8 THE CORRELATION BETWEEN THE Q ANGLE AND LEG HEEL ALIGNMENT AMONG GROUPS IN RIGHT SIDE

\begin{tabular}{|c|c|c|c|}
\hline VARIABLES & N & SIGNIFICANT VALUE & PEARSON CORRELATION \\
\hline Q ANGLE RIGHT & 75 & 0.000 & 0.487 \\
\hline LEG-HEEL ALIGNMENT RIGHT & 75 & 0.000 & 0.487 \\
\hline
\end{tabular}

The above table shows the variables, $\mathrm{N}$ value , significant value $(\mathrm{p}=0.000)$ and pearson correlation between the leg heel alignment and $\mathrm{Q}$ angle among the groups in right side.

TABLE 9 THE CORRELATION BETWEEN THE LEG HEEL ALIGNMENT AND TIBIAL TORSION AMONG GROUPS IN RIGHT SIDE

\begin{tabular}{|c|c|c|c|}
\hline VARIABLES & N & SIGNIFICANT VALUE & PEARSON CORRELATION \\
\hline TIBIALTORSION RIGHT & 75 & 0.000 & 0.741 \\
\hline LEGHEEL ALIGNMENT RIGHT & 75 & 0.000 & 0.741 \\
\hline
\end{tabular}

The above table shows the variables, $\mathrm{N}$ value, significant value $(\mathrm{p}=0.000)$ and pearson correlation between the leg heel alignment and tibial torsion among groups in right side.

TABLE 10 THE CORRELATION BETWEEN THE Q ANGLE AND LEG HEEL ALIGNMENT AMONG GROUPS IN LEFT SIDE

\begin{tabular}{|c|c|c|c|}
\hline VARIABLES & N & SIGNIFICANT VALUE & PEARSON CORRELATION \\
\hline Q ANGLE LEFT & 75 & 0.000 & 0.439 \\
\hline LEGHEEL ALIGNMENT LEFT & 75 & 0.000 & 0.439 \\
\hline
\end{tabular}

The above table shows the variables, $N$ value, significant value $p=(0.000)$ and pearson correlation between the leg heel alignment and Q angle among the groups in left side.

TABLE 11 THE CORRELATION BETWEEN THE Q ANGLE AND TIBIAL TORSION AMONG THE GROUPS IN LEFT SIDE.

\begin{tabular}{|c|c|c|c|}
\hline VARIABLES & N & SIGNIFICANT VALUE & PEARSON CORRELATION \\
\hline Q ANGLE LEFT & 75 & 0.000 & 0.454 \\
\hline TIBIAL TORSION LEFT & 75 & 0.000 & 0.454 \\
\hline
\end{tabular}

The above table shows the variables, $\mathrm{N}$ value, significant value $\mathrm{p}=(0.000)$ and pearson correlation between the $\mathrm{Q}$ angle and tibial torsion among the groups in left side

TABLE 12 THE CORRELATION BETWEEN THE LEG HEEL ALIGNMENT AND TIBIAL TORSION AMONG THE GROUPS IN LEFT SIDE.

\begin{tabular}{|c|c|c|c|}
\hline VARIABLES & $\mathbf{N}$ & SIGNIFICANT VALUE & PEARSON CORRELATION \\
\hline TIBIALTORSION LEFT & 75 & 0.000 & 0.586 \\
\hline LEGHEEL ALIGNMENT LEFT & 75 & 0.000 & 0.586 \\
\hline
\end{tabular}

The above table shows the variables, $\mathrm{N}$ value, significant value $\mathrm{p}=(0.000)$ and pearson correlation between the leg heel alignment and tibial torsion among groups in left side.

TABLE 13 ALL GROUPS COMBINED COMPARISON (KARL PEARSON'S CORRELATION COEFFICIENT)

\begin{tabular}{|c|c|c|}
\hline VARIABLES & RIGHT & LEFT \\
\hline QANGLE-TIBIAL TORSION & $0.520(0.000)$ & $0.439(0.000)$ \\
\hline Q ANGLE - LEG HEEL ALIGNMENT & $0.487(0.000)$ & $0.454(0.000)$ \\
\hline TIBIAL TORSION -LEG HEEL ALIGNMENT & $0.741(0.000)$ & $0.586(0.000)$ \\
\hline
\end{tabular}

The table shows the combined comparison of significant value and pearson's correlation of various groups in right and left side. 
International Journal of Trend in Scientific Research and Development (IJTSRD) ISSN: 2456-6470

TABLE 14 THE COMPARISON BETWEEN THE IDEAL, OVERWEIGHT AND OBESE S
\begin{tabular}{|c|c|c|c|c|c|c|}
\hline ON RIGHT AND LEFT SIDE \\
\hline VARIABLES & \multicolumn{2}{|c|}{ IDEAL } & OVER WIGHT & \multicolumn{2}{c|}{ OBESE } \\
\hline $\begin{array}{c}\text { Q ANGLE-TIBIAL } \\
\text { TORSION }\end{array}$ & 0.275 & -0.311 & -0.12 & 0.509 & -0.032 & 0.169 \\
\hline $\begin{array}{c}\text { Q ANGLE- LEG } \\
\text { HEEL ALIGNMENT }\end{array}$ & 0.184 & 0.131 & 0.568 & 0.009 & 0.878 & 0.420 \\
\hline $\begin{array}{c}\text { TIBIAL TORSION- LEG } \\
\text { HEEL ALIGNMENT }\end{array}$ & 0.055 & -0.359 & -0.031 & 0.22 & 0.36 & -0.092 \\
\hline
\end{tabular}

The table shows the comparison between $\mathrm{P}$ value and pearson's correlation of $\mathrm{Q}$ angle-tibial torsion, $\mathrm{Q}$ angle -leg heel alignment, Tibial torsion-leg heel alignment for right and left leg of ideal, overweight and obese subject.

\section{RESULTS}

Table 1 shows the gender distribution among Group A - Ideal subjects

Table 2 shows the gender distribution among Group $\mathrm{B}$ - Over weight subjects

Table 3 shows the gender distribution among Group $\mathrm{C}$ - Obese subjects

Table 4 Shows the difference between the Q angle on right and left among all the groups .

There was significant difference between IdealOverweight $(p=0.001)$,ideal-Obese $(p=0.001)$,Obese Overweight $(\mathrm{p}=0.001)$ in Right .Ideal - Overwight $(p=0.001)$, Ideal-Obese $(p=0.000)$ in Left .And No significant difference between Overweight-Obese $(p>0.099)$ in left.

Table 5 Shows the difference between the leg heel alignment on right and left among the groups. There was significant difference between IdealOverweight,Ideal-Obese ,Overweight

$\operatorname{Obese}(\mathrm{p}=0.000)$

Table 6 Shows the difference between the tibial torsion on right and left among the groups. There was significant difference between Ideal-Overweight, Ideal-Obese $(p=0.000)$ in both right and left side. No significant difference between Overweight-Obese $(p>0.692)$ in right, $(p>0.097)$ in left.
Table 7 shows correlation the correlation between the $\mathrm{Q}$ angle and tibial torsion in right $\mathrm{p}=0.000$

Table 8 Shows the correlation between the Q angle and leg heel alignment in right $p=0.000$

Table 9 shows the correlation between the leg heel alignment and tibial torsion in right $\mathrm{p}=0.000$

Table 10 Shows the correlation between the $\mathrm{Q}$ angle and leg heel alignment in left $p=0.000$

Table 11 Shows the correlation between the $Q$ angle and tibial torsion in left $\mathrm{p}=0.000$

Table 12 Shows the correlation between the leg heel alignment and tibial torsion in left $p=0.000$

Table 13 Shows all group combined comparison (karl pearson's correlation coefficient)

Table 14 Shows the comparison between the ideal, over weight and obese subjects on right and left side.

\section{DISCUSSION}

A Study was done to find correlation between Q angle ,Tibial torsion and leg heel amongst 25 ideal ,overweight and obese individuals each group. When $\mathrm{Q}$ angle was analysed using ANOVA between ideal, overweight and obese there was significant difference seen in right and left. There was significant difference seen between ideal and overweight, ideal and obese in both right and left but between obese and overweight significant is seen only in right when analysed using ANCOVA.

Amongst 3 groups significant tibial torsion angle difference was seen in right (0.000) and left 
(0.000). There was also significant difference between ideal and overweight, ideal and obese in both right and left. Study conducted by P. P. Popat, A. R Parekh to study biomechanical variation of joint angles in overweight females found that there was significant increase in calcaneal eversion and angle toe out in overweight than compared to ideal females .They also found that there is positive correlation between calcaneal eversion and angle toe out.

In the present study there was significant difference in $Q$ angle between ideal and overweight in right $(p=0.001)$, between ideal and obese in right $(p=0.000)$ between obese and overweight $(p=0.044)$. And also significant difference was seen between ideal and overweight in left $(\mathrm{p}=0.001)$, also between ideal and obese in left $(p=0.000)$. But no significant difference was seen between obese and overweight in left $(\mathrm{p}=0.099)$.

Tibial torsion between ideal and overweight in right and left $(p=0.000)$, and between ideal and obese in right and left $(\mathrm{p}=0.000)$. But no significant difference between obese and overweight in right $(p=0.692)$ and in left $(\mathrm{p}=0.097)$.

Leg-heel alignment significant difference is seen between normal and overweight, and between normal and obese and between obese and overweight in both right and left $(\mathrm{p}=0.000)$. A study previously done indicate that the $\mathrm{Q}$ angle increases with increased tibial external rotation, There is increased load of weight bearing joint with increase in weight .Due to increased body mass obese people have greater absolute knee adduction moments and also compensatory gait patterns like slow walking and increased toe - out angle .when femoral ante version is excess it may lead to more medial rotation of femur leading to displacement of patella medially. Femoral ante version may be related to intoeing gait which is compensated with external rotation of tibia on femur causing tibial tuberosity to displace more laterally.

The torsion is transmitted to hind foot and ankle joint .Increased anterior pelvic tilt and navicular drop result in rotational changes in the femur and tibia displacing the patella medially and the the tibial tuberosity laterally. Increased medial joint loading, is evidenced by a greater knee - joint adduction moment, has also been frequently noted in individuals with OsteoArthritis.
Study done by G. C Michael et al. found that with greater externally rotated legs there was significant increase in calcaneal eversion.

We can conclude from the study due to weight there are alternations in Q angle, tibial torsion ang leg -heel alignment

\section{CONCLUSION}

Due to weight there are alternations in Q angle, tibial torsion ang leg -heel alignment, there is correlation between leg heel alignment, Qangle, tibial torsio

\section{REFERENCE}

1. Shanmugapriya C, Vinodha R. The Effects of Aerobic Training on Cardiovascular Fitness in obese Sedentary Females. Res Rev J Med Health Sci. 2014Jul;30.

2. Butterworth P A, Landorf K, Smith S E, Menz H $B$. The association between body mass index and musculoskeletal foot disorders: A systematic review. Obesity reviews. 2012 March.

3. Popat P P, Parekh A R. Biomechanical variation of joint angles in overweight females. Journal of Obesity and Metabolic Research. 2014 Nov1.

4. Pi-Sunyer F X, Dietz W H, Becker D M, Foreyt J $\mathrm{P}$, Bouchard C, Garrison RJ et al. Clinical guide lines on the identification, evaluation, and treatment of overweight and obesity in adults. NIH publication.1998 Sept

5. Snehalatha $C$, Viswanathan V, Ramachandran A Cutoff values for normal anthropometric variables in Indian adults. Diabetes Care. 2003.

6. Noor M I, Koon P B, Hashim Z. Strategy for the prevention of obesity- Malayasia. Malaysian Association for the Study of Obesity; 2005.

7. Gadzik J. Quetelet's equation, upper weight limits and BMI prime. 2009. Avaliable form: http:// www.surgicalassociatesofwestport.com.html

8. Wearing S. C, Hennig E. M, Byrne N. M, Steele J. R,Hills A. P. Musculoskeletal disorders associated with obesity: a biomechanical perspective. Obesity Reviews. 2006 Aug; 7.

9. Sarkar A, Singh M, Bansal N, Kapoor S. Effects of obesity on balance and gait alterations in young adults. Indian j physiol pharmacol. 2011January. 
10. Perkins S. Obesity and ankle [Internet]. [Updated 2015 Jan 28]. Available form: http://www.Obesity and Ankle Pain LIVESTRONG_COM.mht

11. Kisner C, Colby L A. Therapeutic exercise. 5th Edition. New Delhi: Jaypee; 2007.

12. Magee D J. Orthopaedic physical assessment. $5^{\text {th }}$ Edition. New Delhi: Elsevier; 2008.

13. Aparna S, Meenakshi S, Nitesh B, Seema K. Effects of obesity on balance and gait alterations in young adults. Indian J PhysiolPharmacol 2011.

14. Anh D N, Michelle B C, Beverly L, Sandra J S.Relationship between lower extremity alignment and quadriceps angle. Clin J Sport Med. 2009 May; 19.

15. Levinger P, Hylton B M, Adam D M, John R B, Jullian A F, Neil R B. Relationship between foot function and medial knee joint loading in people with medial compartment knee osteoarthritis. Journal of foot and ankle research. 2013. 